\title{
Masculinidades indígenas y empoderamiento femenino
}

\section{Indigenous masculinities and female empowerment}

\author{
José Luis García Horta** \\ Colegio de Postgraduados, Montecillo, México.
}

\author{
Emma Zapata Martelo*** \\ Colegio de Postgraduados, Montecillo, México.
}

Recibido: 27 de enero de 2018. Aprobado: 15 de marzo de 2018 . DOI: $10.25100 /$ lamanzanadeladiscordia.v13i1.6713

Artículo de investigación

\begin{abstract}
Resumen: El trabajo analiza los cambios en la forma en que los esposos/compañeros de mujeres otomies expresan la masculinidad a partir de la inserción de ellas en el mercado de trabajo por medio del microfinanciamiento de ProMujer. Se responderá a la pregunta ¿Cómo influye el empoderamiento económico de mujeres indigenas en las formas en que los hombres expresan su masculinidad? El trabajo se desarrolló con 20 hombres/esposos de mujeres integrantes del Centro Focal de ProMujer ubicado en Ixmiquilpan, Estado de Hidalgo, a quienes se les hizo una entrevista en profundidad sobre su posición respecto al trabajo de las mujeres y a los ingresos aportados por ellas al grupo doméstico. Los resultados muestran un discurso que manifiesta conflictos, contradicciones y resistencias de ellos ante la nueva situación económica. No obstante, reconocen el aporte económico de las mujeres sin el cual
\end{abstract}

no podrían proveer todas las necesidades de sus grupos domésticos, pero ellos no se incorporan a las actividades estereotipadas como femeninas. En los discursos de los esposos/compañeros se nota la dificultad y el miedo que tienen al asimilar la independencia de las mujeres, al ser gestoras de recursos, participar en diversas actividades, relacionarse con otras mujeres y reconocerse en un proceso de cambio.

Palabras clave: Microcrédito; empoderamiento; masculinidades; género.

Abstract: This article analyzes the changes in the way the husbands/partners of Otomi women expressed their masculinity after the inclusion of their spouses in the labor market through the microfinance project of ProMujer. We seek to answer the question of How does the economic empowerment of indigenous women influence the ways

\footnotetext{
*Este artículo resulta de la Tesis Doctoral titulada "Y ellas trabajando a golpe de sol... y con el metate también". Masculinidades y empoderamiento de las mujeres a partir de las microfinanzas. El documento se presentó para optar por el grado de Doctor en Ciencias en el Colegio de Postgraduados, Montecillo Estado de México.

**Doctor por el Colegio de Postgraduados y especialista en Género y economía por la UNAM. Las investigaciones realizadas hablan del papel que tienen las microfinanzas en el empoderamiento de las mujeres y como elemento significativo para que ellas superen las condiciones de pobreza en la que viven. Profesor de Metodología de la Investigación” en el Colegio de Bachilleres del Estado de México. Autor de varios artículos publicados en México y en el extranjero. Correo electrónico: ighorta@.colpos.mx.

***Doctora en Sociología, Universidad de Texas, en Austin. Es profesora Investigadora Titular en el Colegio de Postgraduados, en Montecillo, Estado de México donde ha trabajado por treinta y siete años. Impulsó la especialidad sobre estudios de género en la institución, dirigidos específicamente a la problemática de mujeres y hombres del sector rural. En 2001 recibió el Premio Internacional de Investigación en Países en Desarrollo, por la Universidad Justus-Liebig, en Giessen, Alemania. En 2006 el Premio Nacional María Lavalle Urbina. Numerosos artículos de su autoría sobre las relaciones de género en el ámbito rural han aparecido en revistas nacionales y extrajeras. Pertenece a la Academia Mexicana de Ciencias desde 1997; es integrante del Sistema Nacional de Investigadores, Nivel III. En 2010 le fue otorgado el Premio Estatal de Ciencia y Tecnología, Correo electrónico: emzapata@colpos.mx.
} 
in which men express their masculinity? The research work was carried out among 20 of the husbands/partners of women belonging to the Centro Focal de ProMujer located in Ixmiquilpan, Hidalgo. An in-depth interview was used to find out their stance towards women's work and the income they bring to their households. The results show a discourse in which men display conflicts, contradictions, and resistance towards this new situation: while they recognize the economic contribution of women (without which they could not fulfill all the needs of the household as they did in the past), they resist taking part in stereotypical female activities. In their discourses, one can see the difficulties and fear they experience when assimilating the newly gained independence of women, who as novel resource managers participate in different activities, interact with other women, and salute their process of change.

Keywords: Micro-credit; empowerment; masculinities; gender.

\section{Introducción}

Las relaciones entre hombres y mujeres están atravesadas por mecanismos de poder, que condicionan el posicionamiento social y cultural de cada género en los distintos ámbitos de la vida social. Si bien son necesarios muchos componentes para alcanzar la igualdad en el orden de género, un elemento esencial consiste en cuestionar las estructuras, creencias, prácticas e instituciones que sostienen los privilegios acumulados de los hombres y las normas poco equitativas. Se trata de elementos que han afectado a las mujeres, pero también a los hombres, niños y niñas, y que no pueden modificarse sin la participación de ellas/ellos mismos/as. Sin embargo, a pesar del papel fundamental que hombres y niños pueden desempeñar en los esfuerzos para promover los derechos y el empoderamiento de las mujeres y la igualdad de género, todavía es un recurso que se ha explorado muy poco (Ricardo, 2014).

Existen estudios sobre las relaciones de género como el de Salinas y Arancibia (2006) y Salinas (2007), en los que se evidencia cómo por una parte los hombres valoran positivamente los avances y cambios socioculturales que ha tenido el país y el mundo en general, permitiendo una mayor participación de las mujeres en el ámbito público, pero por otra en los discursos se están develando las tensiones que configuran la crisis de la masculinidad, escenario que responde a nuevas demandas y ajustes en las relaciones de género.

Entre los cambios a nivel global, la incertidumbre en el mercado de trabajo ha propiciado que las mujeres cuando son jefas de familia busquen alternativas para el sustento de sus hogares o cuando están casadas, completen el ingreso de sus compañeros. Como consecuencia, los varones han dejado de ser los proveedores únicos, debido a que sus ingresos son cada día más insuficientes para hacer frente a las demandas familiares lo que les incomoda y los llena de incertidumbre.

Con las crisis económicas y los cambios globales, el ordenamiento de género tradicional en el espacio privado comienza a debilitarse y con ello también las relaciones de poder binarias hombre-activo/ mujer-pasiva. La pérdida del papel de proveedores del grupo familiar tiene implicaciones que afectan su masculinidad y el ejercicio de su poder.

La incorporación de las mujeres al mercado de trabajo ha significado mayor autonomía, y una participación directa en la manutención de la unidad doméstica, este proceso no ha estado exento de dificultades, pues los quiebres de las relaciones de pareja, la violencia doméstica y la incapacidad del varón para proveer a su familia, son algunos de los factores desencadenantes de la crisis que vive actualmente la familia nuclear patriarcal (Salinas y Arancibia, 2006; Salinas, 2007).

En el estudio de Christine Ricardo (2014), publicado por la Alianza MenEngage en colaboración con ONU-Mujeres y UNFPA, retoma el trabajo de Gary Barker et al., (2013) para mencionar que algunos hombres, especialmente en las zonas más pobres del mundo, suelen considerar que la igualdad de género es parte de una agenda impuesta desde afuera, que se opone o les es contraria. Aunque no hay una asociación clara entre la pobreza y mantener opiniones antagónicas en relación con la igualdad de género, la investigación sugiere que es menos probable que los hombres que se sienten económica o socialmente excluidos apoyen la igualdad de las mujeres.

En los últimos años se ha impulsado la inserción de las mujeres al mercado de trabajo, y uno de los mecanismos empleados para lograrlo es el microfinanciamiento. Como propuesta, los 
gobiernos han impulsado políticas públicas destinadas a solucionar los acuciantes problemas de desempleo y pobreza dentro de las cuales existen proyectos productivos que promueven varias instancias gubernamentales con este fin. El microfinanciamiento fue propuesto por las Naciones Unidas en 2005 y dirigido a solucionar la pobreza como uno de los grandes problemas que a escala mundial enfrenta el mundo contemporáneo, propuesta retomada por muchos colectivos públicos y privados. Se supone que el importe del microcrédito ${ }^{1}$ ha de utilizarse para poner en marcha proyectos que permitan a las beneficiarias integrarse en una actividad productiva y por ende en la sociedad de donde han estado excluidas por no contar con respaldos económicos para gestionar recursos para un negocio propio (García y Lens, 2007).

Con variaciones en las formas y en los montos prestados, la Industria del Microfinanciamiento (IMF) se ha extendido por todo el mundo, la mayor parte de estos (82\%) según el último informe presentado en la Cumbre del Microcrédito, celebrada en Washington en 1997, fueron asignados a mujeres.

En América Latina (AL) la IMF ha experimentado un éxito sin precedentes en sus esfuerzos por ampliar los servicios financieros y cubrir las demandas de las poblaciones marginadas. Desde finales de los ochenta, el número de clientes de microfinanzas ha aumentado de manera constante, lo que ha convertido a AL, junto con el Sudeste Asiático, en una de las regiones con el mayor crecimiento de este sector. Los servicios financieros están ahora al alcance de cerca de 6 millones de hogares de bajos ingresos en AL y el Caribe (Navajas y Tejerina, 2007).

En el microfinanciamiento subyacen varios paradigmas, en el caso de ProMujer², uno de ellos se

\footnotetext{
${ }^{1}$ Una característica que distingue al crédito del microcrédito es que este último no está jurídicamente ligado a un contrato. Se basa en la confianza, no en procedimientos legales y de sistema. Para Lacalle (2002) y para la Organización de las Naciones Unidas para la Alimentación y la Agricultura (FAO, 2000), el objetivo final del microcrédito es mejorar las condiciones de vida de los más desfavorecidos y se constituye en una herramienta para reducir las diferencias en el acceso a los recursos financieros.

${ }^{2}$ ProMujer llegó a México en 1992, y a través de sus oficinas llamadas Centros Focales (CF) ofrece sus productos a mujeres y hombres que viven en los estados de Hidalgo, México, Querétaro, Puebla, Tlaxcala, Veracruz y el Distrito Federal (García, 2013).
}

analiza en este documento y es concebido como el alivio a la pobreza, centrado en mejorar el bienestar de las personas mediante la capacitación, alfabetización, provisión de servicios de seguridad social y la instalación de infraestructura. Los instrumentos para lograr estos objetivos son la adjudicación de pequeños préstamos que van acompañados con esquemas de ahorro coercitivos (García, 2013).

Al respecto, Zapata, Vázquez-García, AlbertiManzanares, Pérez-Nasser, López-Zavala, FloresHernández, Hidalgo-Celerié, Garza-Bueno (2003) indican que el neoliberalismo ha promovido el autofinanciamiento de la población de escasos recursos a través de los microcréditos. De acuerdo con estas autoras, los estudios más críticos, señalan que el microcrédito no ha resuelto el problema estructural de la pobreza, el alcance de este instrumento se reduce a proporcionar opciones de autoempleo para que las usuarias puedan obtener ingresos.

Los microcréditos no se dirigen especialmente a las mujeres sólo porque éstas sean las que cumplen la mayor parte de las veces el requisito de elegibilidad (Lacalle, 2002), en primer lugar, se dirigen a ellas porque han sido segregadas de los recursos económicos, sociales y políticos en sus países. También, se ha comprobado que las mujeres son capaces de derivar mayores beneficios económicos para los integrantes de sus familias si se les compara con los hombres (Yunus, 1999). Asimismo, varios estudios han demostrado que las mujeres de las áreas rurales contribuyen más con sus ingresos al bienestar del hogar que los hombres y que tienen un mayor interés en pagar sus préstamos (Zapata et al., 2003). Para Garza-Bueno (2005) el microcrédito es una vía incluyente para las personas pobres, pues amplía sus oportunidades de vida, especialmente para mujeres, dado que influye de manera directa en sus posibilidades de crecimiento y empoderamiento.

En el entendido de que para comprender las masculinidades se deben entender las feminidades, ya que el género es un sistema de interacciones sociales y no un sistema de compartimientos estáticos, es decir, lo que afecta a unas implica a otras, en este artículo se propone analizar si ha cambiado la identidad masculina de los esposos/ 
compañeros de las mujeres indígenas que participan con los microfinanciamientos de ProMujer, cuáles son los cambios percibidos por hombres y mujeres en la significación y práctica de la masculinidad en las relaciones de género, producto de la emergencia de las mujeres como nuevas actantes políticas y sociales. Para ello se analizan 20 entrevistas en profundidad realizadas con esposos/compañeros de mujeres que reciben microfinanciamiento de ProMujer en Ixmiquilpan, estado de Hidalgo.

En la primera parte del artículo se proponen algunos planteamientos teóricos sobre las masculinidades y los cambios que ocurren cuando las mujeres se insertan en procesos económicos. Posteriormente, se aborda la metodología empleada y la zona de estudio. Seguidamente, se describe el perfil de mujeres y hombres en esta relación de cambio y empoderamiento. Luego, los hombres con sus propias voces exponen su sentir y su visión ante la nueva situación. Finalmente, se llega a algunas conclusiones.

\section{Reflexión teórica sobre las masculinidades}

Son los estudios de género los que comienzan a abordar las masculinidades ${ }^{3}$ y las formas en las que se expresan. Connell (2008), como uno de los pioneros en éstos, señala que la masculinidad no es una categoría biológica sino una construida histórica y socioculturalmente. El género como práctica social se refiere a los cuerpos y lo que los cuerpos hacen, pero no se reduce a ello, ya que la práctica social es creadora e innovadora, no autómata y da lugar a las relaciones de género que en el escenario productivo constituyen una de las estructuras más importantes de la sociedad. El género es una estructura compleja en la que se superponen varias lógicas diferentes, lo que es fundamental para el análisis de las masculinidades. El género como configuración de la práctica puede ubicarse en varias estructuras y seguir trayectorias históricas diferentes. La masculinidad, lo mismo que la feminidad, siempre está asociada a contradicciones internas y rupturas históricas. El autor propone un

\footnotetext{
${ }^{3}$ Aunque se ha avanzado en los estudios sobre las masculinidades no son ajenos a imprecisiones de tipo teórico y metodológico, y por lo tanto han arrastrado ambigüedades, incluso algunos casos contradicciones, es decir, la construcción teórica ofrece aún retos importantes tanto para la acción como para la política (Careaga y Cruz, 2006).
}

modelo de estructura de género con tres dimensiones: 1) Relaciones de poder, eje principal en el sistema de género euro norteamericano ${ }^{4}$; 2) relaciones de producción, que se refieren a la asignación de tareas y consecuencias económicas de la división genérica del trabajo; 3) Cathexis, que permite analizar las relaciones involucradas en la práctica, por ejemplo, si son coercitivas o consensuadas. La formación de papeles acorde al género es parte de una estructura social, que está impregnada, entre otras cosas por el poder, la desigualdad y la represión.

La masculinidad se refiere específicamente a los papeles que los hombres realizan y que responden a patrones preestablecidos, aprendidos, interiorizados y transmitidos por generaciones. Se va construyendo socialmente en un proceso permanente de prácticas y por ello es transformable a través de procesos de concientización y desarrollo individuales y colectivos.

El interés por los estudios de las masculinidades lo explican Herrera y Rodríguez (2001) y aparece cuando se hizo un viraje del enfoque $\mathrm{MED}^{5}$ de los años 70 y 80 , que sólo abordaba a las mujeres, y dejaba de lado la construcción de las identidades genéricas, masculinas y femeninas, productos históricos que varían con la cultura y el contexto diferente a través del ciclo vital. El viraje se dio hacia el $\mathrm{GED}^{6}$, postura que incluyó la comprensión del género como categoría relacional y aborda la forma como se vinculan mujeres y hombres cultural y socialmente partiendo de sus diferencias biológicas. Se buscó entender cómo se construye el poder patriarcal, qué privilegios tiene el poder masculino y qué implica ocultar ciertas fragilidades. Con el GED surge la necesidad de mirar el papel de los hombres y las masculinidades como una forma de superar las diferencias para alcanzar la equidad.

Otros autores como Campos y Salas (2008) incluyen en la masculinidad la necesidad de cumplir con roles sociales que apuntan a una jerarquía por lo que asocian la masculinidad al poder y a la autoridad. En esta misma línea de pensamiento Kaufman (2008) habla de las "paradojas del poder" que según

\footnotetext{
${ }^{4}$ Es el que ha dominado la cultura por el impacto de la colonia. Hoy se están analizando otras masculinidades como la indígena, la de los hombres negros entre otras.

${ }^{5}$ Mujeres en Desarrollo.

${ }^{6}$ Género en el Desarrollo.
} 
él están al centro de la vida de los hombres. Para este autor, los hombres han desarrollado sociedades donde ejercen el poder y control sobre mujeres, niños y niñas. Incluso han mantenido el control sobre otros hombres con base en la división de la sociedad en clases. El poder sobre seres humanos se ha extendido hacia la naturaleza con formas cada vez más elaboradas. Este proceso descansa en el poder de manejar, dominar y controlar a las personas y al mundo a su alrededor.

Sin embargo, la cultura dentro de la cual subyacen las relaciones de poder es variable. Al ubicar las masculinidades como producto histórico y cambiante con la cultura y la economía, Sambade (2010) indica que no se pude negar que los cambios macro y micro ocurridos durante los últimos años del siglo XX generaron la apertura del mercado laboral para las mujeres y posibilitaron cierto empoderamiento social y económico. Se suponía que esta situación aunada al movimiento feminista acabaría con la superioridad masculina, sin embargo, ésta no ha desaparecido, por el contrario, se ha desestructurado, fragmentado y adquirido nuevas formas.

También han puesto en evidencia las causas del malestar que algunos hombres experimentan ante la pérdida de control de aquellos espacios donde tradicionalmente adquirían su identidad, el espacio público. Progresivamente las mujeres ocupan estos ámbitos con una posible emancipación política $\mathrm{y}$ económica. Al mismo tiempo los hombres han dejado de ser los proveedores únicos del grupo doméstico debido a las condiciones de trabajo, a los cambios en la economía y la globalización de la pobreza (Sambade, 2010).

Sambade (2010) enfatiza que la persistencia de ciertas prácticas de discriminación por parte de los hombres y dominación de las mujeres es porque sigue existiendo una situación estructural de desigualdad que perpetúa el mayor acceso al poder y privilegios sociales de los hombres, a pesar de la fragmentación de la cosmología androcéntrica y falo narcisista.

Al respecto, Montesinos y Carrillo (2010) hablan de dos períodos que llaman tradición y modernidad, donde consideran la interrelación existente entre la economía, la política y la cultura, y plantean que la estructura más significativa de la sociedad es la proveniente de la división sexual del trabajo, y, por tanto, la más reveladora para definir la identidad tanto de hombres como de mujeres. Para estos autores al superar la tradición, se supera la división sexual del trabajo, lo que inevitablemente transforma la identidad de uno y otro género, porque en principio ésta ya no excluye a la mujer del trabajo remunerado y rompe con el confinamiento de ella en el espacio privado, se diluye la figura de la familia nuclear, por lo que la modernidad abre paso a nuevas formas de organización familiar.

La forma hegemónica de masculinidad legitima el patriarcado y asegura la dominación de los hombres y la subordinación de las mujeres, exige la heterosexualidad forzada como constituyente de la identidad de género y de la práctica en función del género; y posee el monopolio de violencia. Para que esta forma de masculinidad pueda imponerse como hegemónica, es necesario el apoyo de un poder institucional. El ideal cultural de masculinidad debe ponerse en escena y sancionarse permanentemente en los niveles de dirección de la economía, del ejército, de la política, etcétera. La masculinidad se reproduce gracias al trabajo de socialización sobre todo en la familia y la escuela (Zapata-Galindo, 2001).

En su trabajo sobre "El poder masculino" el sociólogo Pierre Bourdieu (2000) señala las formas mediante las cuales persisten y se mantienen, hasta el día de hoy en la cabeza de los individuos, elementos constitutivos del poder masculino. Por un lado, el poder masculino está inscrito en "la objetividad de las estructuras sociales y en la subjetividad de las estructuras mentales". Bonino (2000), expone que existe una creencia matriz de la masculinidad hegemónica: la ideología de la supremacía masculina sobre las mujeres. Esta ideología o creencia sostiene la idea de que los varones y las mujeres son diferentes y desiguales por naturaleza. Según las diferencias "naturales", los varones, sujetos libres y racionales, estarían capacitados para el trabajo productivo y la deliberación política, por lo que les corresponde el monopolio de la esfera social pública; mientras que las mujeres, sujetos emocionales y dependientes, estarían esencialmente capacitadas para el trabajo reproductivo y de cuidado de hijos e hijas, por lo 
que les es propia la permanencia en la esfera social privada. Por lo tanto, la ideología de la supremacía masculina justifica la división sexual del trabajo y constituye un dispositivo de saber-poder que perpetúa la desigualdad social y política entre mujeres y varones.

Al lado de las demandas por la equidad de género existe un tema emergente que apela por el reconocimiento de los derechos de diversidades subalterizadas y de autonomía indígenas en contextos interculturales y globalizados. Esta paradoja constituye el marco problemático y complejo de los estudios emergentes de las masculinidades indígenas (Díaz-Cervantes, 2015). Para este autor, la sociedad mexicana tiene un imaginario paradójico de las culturas indígenas: por una parte, las considera como sociedades donde persiste un patriarcado extremo y por otra como sociedades armónicas y sin conflicto aparente de las relaciones de género. Por ello los estudios de las masculinidades indígenas requieren poner a la luz los sistemas simbólicos indígenas que han sido resignificados y perviven, además la internalización de contenidos culturales occidentales permeados por el patriarcado y el heterosexismo (2015).

Estos postulados teóricos servirán para analizar los posibles cambios en las masculinidades de los esposos/compañeros de las mujeres que reciben microfinanciamiento con los que han impulsado un proyecto productivo, y que les permite teóricamente iniciar procesos de empoderamiento económico.

\section{¿Cómo se eligieron a las mujeres y hombres para la investigación?}

De forma somera se aborda el papel de la microfinanciera ProMujer, ya que se parte del posible empoderamiento de las mujeres y los cambios de sus esposos/compañeros a partir de los microproyectos. ProMujer ha replicado la metodología de Grameen Bank, ${ }^{7}$ basada en la prestación de servicios de microcrédito para propiciar el autoempleo de las mujeres, las responsabiliza de su manejo, de la puesta en marcha de un negocio con el cual amplíen sus capacidades de gestión, e impacten en los ingresos familiares con implicaciones para los miembros

\footnotetext{
7 Banco fundado por Muhammad Yunus en Bangladesh. Para algunos autores, marca el inicio del microcrédito en la época moderna.
}

del grupo doméstico. Para realizar el análisis se combinaron datos cuantitativos y cualitativos. Del universo de mujeres (951) que ProMujer atendía en 2010 solo se consideraron 489. Para el cálculo de la muestra, se aplicó la fórmula de varianza máxima y se obtuvo una muestra de 85 mujeres con $95 \%$ de confiabilidad y $10 \%$ de precisión. Además, del cuestionario cuantitativo que se aplicó a toda la muestra, se realizó una entrevista a profundidad a 20 compañeros de estas mujeres con un cuestionario específico para ellos.

El tema que interesa analizar aquí ${ }^{8}$ son las posibles transformaciones de las masculinidades de los esposos/compañeros. Por ello las preguntas para los hombres tuvieron un matiz distinto respecto al utilizado con las mujeres, puesto que se consideraron aspectos relacionados con su masculinidad, las formas mediante las cuales perciben el trabajo productivo-reproductivo que realizan las mujeres, así como también los aspectos relacionados a la división sexual del trabajo. Debido a ello, cuatro varones se negaron a continuar con la entrevista, solicitaban evitar preguntas respecto de lo que significaba "ser hombre" o las referidas a su participación en el trabajo doméstico. Todas las entrevistas que fueron codificadas y analizadas con el software ATLAS.ti, versión 6.

\section{Ixmiquilpan zona de otomíes}

El municipio de Ixmiquilpan es el lugar donde se realizó el trabajo y se encuentra en la parte central de la República Mexicana. Gran número de sus pobladores y los de regiones aledañas pertenecen al grupo indígena de los otomíes, quienes luchan por mantener su cultura en una sociedad cambiante; en la generalidad de las comunidades ellos y ellas se siguen reconociendo como tales y defienden sus tradiciones, usos y costumbres, practican ritos que refuerzan su identidad colectiva y ejercen coacción frente a quienes pretenden violentar sus normas (Moreno, Garret y Fierro, 2006). Uno de los entrevistados expuso lo siguiente:

Bueno acá es una región indígena y yo creo que acá se marca mucho la diferencia entre hombres

\footnotetext{
${ }^{8}$ Dos artículos se han publicado con el análisis de las mujeres que participan en ProMujer y aparecen citados en la bibliografía.
} 
y las mujeres, y de hecho a nosotros siempre tuvimos que trabajar mucho en el campo y sin en cambio, las mujeres lo que hacían era ayudar en el hogar y una que otra ahí a pastorear... ("Enrique", comunicación personal, 4 de abril de 2012).

La economía de Ixmiquilpan gira alrededor de tres actividades: agricultura, ganadería y minería. La región incluye un vasto valle árido y seco con presencia de la Sierra Madre Oriental, que da origen a sistemas de riego que permiten a algunas comunidades sembrar hortalizas, maíz para autoconsumo y alfalfa para el comercio y el desarrollo de parques acuáticos cuya explotación sirve para sostener la economía de algunas familias.

Los otomíes lejos de permanecer pasivos han desarrollado una industria alrededor del maguey, planta que forma parte de la economía básica a nivel familiar. La pobreza de la zona revela la gran movilidad de hombres hacia otros estados de la República en búsqueda de trabajo y también al extranjero.

Son diversos los factores que inciden en la vida de las comunidades y que incluso llegan a fracturarlas internamente, aunque es notable que la generalidad de éstas se siga reconociendo como tales y hacen defensa de sus tradiciones, usos y costumbres, practican ritos que refuerzan su identidad colectiva $\mathrm{y}$ ejercen coacción frente a quienes pretenden violentar sus normas (Moreno et al., 2006).

\section{Las mujeres protagonistas de los microcréditos y sus quehaceres}

Aunque el énfasis se hará en las formas en las que los varones ven el microfinanciamiento de sus compañeras/esposas se considera importante conocer el perfil de las usuarias del microcrédito y los negocios que emprenden con ellos:

De la muestra (85 mujeres) residían tanto en comunidades rurales como urbanas marginadas, $10.6 \%$ son jóvenes menores de 30 años, $38.8 \%$ tiene entre 31 y 40 años, y $41.1 \%$ de 41 a 60 años. El resto de las mujeres (9.4\%) es de más de 60 años. Todas se encuentran en una relación de pareja, sean casadas o en unión libre. Respecto a la escolaridad, la mayoría estudió la primaria (42.4\%), 41.2\% el

\footnotetext{
${ }^{9}$ Con el fin de mantener el anonimato de los entrevistados se procedió a asignarles un seudónimo a cada uno.
}

nivel de secundaria, 15.3 preparatoria y solo una persona alcanzó el nivel universitario.

Las beneficiarias solicitan con mayor frecuencia préstamos cuyo monto oscila entre los $\$ 3,001^{10} \mathrm{y}$ $\$ 6,000$, siendo las usuarias de la zona urbana las que más solicitan este tipo de montos. El préstamo más pequeño, entre $\$ 1.0$ y $\$ 300.00$ ocupa el segundo lugar de las preferencias, siendo las mujeres que viven en las zonas rurales las que más optan por este tipo de microcréditos. Si a este dato le adicionamos el porcentaje de las usuarias que le requieren a ProMujer préstamos entre $\$ 6,001$ y $\$ 10,000$ pesos, se puede establecer una proyección real del tipo de población atendida y al mismo tiempo permite dimensionar el tipo de micronegocios que se logran impulsar o reanudar. Finalmente, existen aproximadamente entre 12 y 15 personas que gestionan préstamos entre $\$ 10,001$ y $\$ 20,000$ pesos. La información aparece en la Figura 1.

Fuente: Elaboración propia.

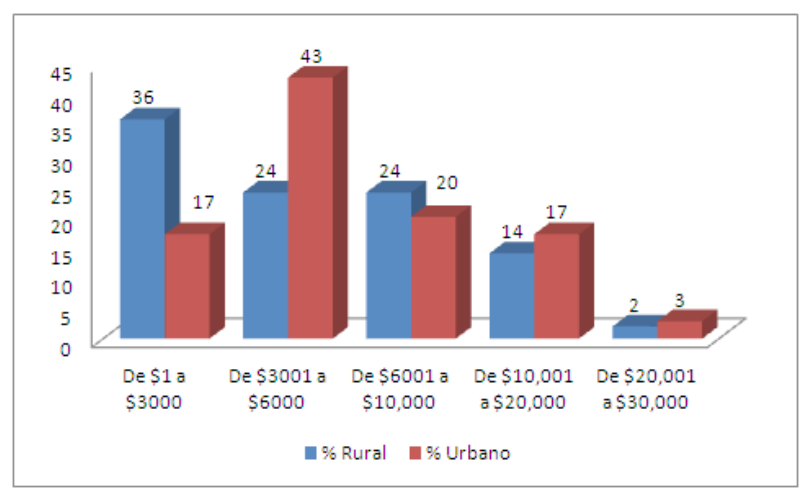

Figura 1. Tamaño del microcrédito solicitado.

Como se puede observar, realmente el microcrédito que obtienen es muy pequeño, sin embargo, lo que pueden hacer con ello, ha cambiado sus relaciones y actividades al interior del grupo familiar, debido a que al aportar ellas un poco al ingreso familiar, les da una postura de ruptura, de mayor poder en la toma de decisiones, aun cuando no se cuestionen los estereotipos de feminidad y masculinidad establecidos. Se podría decir que el microcrédito aporta al empoderamiento económico de las mujeres, aunque no en el empoderamiento familiar y de las relaciones cercanas.

\footnotetext{
${ }^{10}$ En adelante, las sumas de dinero a las que se hace referencia se encuentran en pesos mexicanos.
} 


\section{Actividad destino del microcrédito}

El trabajo que realizan las mujeres frecuentemente se ve adscrito a empleos segmentados, carentes de seguridad social y altamente flexibilizados. Los negocios que emprenden, siguiendo las categorías establecidas por el Instituto Nacional de Estadística y Geografía de México (INEGI) (2013), se enmarcan en actividades comerciales denominadas "al por menor" "11, excepto las agropecuarias, que tienen una categoría especial porque se contabilizan en el PIB nacional.

E127\% delas mujeres, con el microcréditopreparan alimentos, que comercializan en la vía pública, o en pequeñas cocinas económicas y en los mercados municipales. En segundo lugar, se encuentra la venta de diversos productos por medio de catálogos. No las emplea ninguna firma, no tienen salario e invierten sus recursos para financiar los productos que venden. Siguen en importancia las actividades agropecuarias. Los lugares cuarto y quinto los ocupan un conjunto de actividades relacionadas con venta de productos perecederos de origen agropecuario ${ }^{12}$, en estas unidades las mujeres comercializan artículos que, debido a su estructura orgánica, son susceptibles de entrar en estado de descomposición y requieren de refrigeración. La comercialización de artículos perecederos la realizan 13\%. Finalmente, se pueden ubicar a las usuarias que dijeron haber solicitado el microcrédito para que su pareja hiciera uso y disfrute de éste, ellas representan $2 \%$ de la muestra.

${ }^{11}$ El INEGI (2013), establece que este sector comprende unidades económicas dedicadas principalmente a la compra-venta (sin transformación) de bienes de consumo final para ser vendidos a personas y hogares, así como a unidades económicas dedicadas solamente a una parte del proceso (la compra o la venta). Los comercios al por menor que venden bienes propios son conocidos como agencias, depósitos, tiendas, supermercados o derivan su nombre de los productos que comercializan. Y los comerciantes minoristas que venden o promueven la compra-venta a cambio de una comisión o pago son conocidos como agentes de venta, corredores de mercancías, comisionistas, consignatarios, intermediarios del comercio al por menor, agentes importadores y exportadores. Los comercios al por menor tienen una o más de las siguientes características: 1) Atraen clientes por la ubicación y el diseño del establecimiento; 2) Tienen extensa exhibición de mercancías para facilitar a los clientes su selección; 3) Hacen publicidad masiva por medio de volantes, prensa, radio, televisión, etcétera. Los comercios al por menor pueden también proporcionar servicios integrados a la venta de bienes, como empaquetado, envasado y entrega a domicilio.

${ }^{12}$ De acuerdo con las categorías dadas por el INEGI (2013), los productos perecederos son aquellos artículos que durante su proceso, venta y comercialización requieren de un especial cuidado e incluso de la refrigeración. Se incluyen las tortillerías, los abarrotes, venta de carnes frías, venta de quesos y cremas a granel.
Los espacios donde desarrollan sus actividades son muy limitados, puesto que se trata de actividades de carácter informal. Si bien pueden favorecer procesos de empoderamiento económico, éstas se centran en microprácticas y formas culturales promulgadas, construidas y legitimadas en términos de subordinación de género, quedándose solo en microespacios, que han sido asignados cultural y socialmente a las mujeres (García, Ayala y Zapata, 2015), pero también implica que salgan de sus hogares, es decir, al vender algún producto, ya sea en un establecimiento, en las calles y/o de casa en casa, requiere que salgan de su confinamiento y puedan platicar con otras personas, siendo este un elemento que permite a las mujeres autonomía y participación en la toma de decisiones.

El hecho de trabajar una microempresa no significa que las mujeres se liberen del trabajo doméstico realizado como deber exclusivo del ama de casa y por lo tanto parte de su rol genérico. Se encontró que quienes aportan a esta actividad generalmente son las hijas, mientras que los esposos/ compañeros sólo participan en algunas de las que requiere menor tiempo (García et al., 2015). Se incrementa así el poder de los hombres y el control sobre el tiempo mediante dobles y triples jornadas. Además, se perpetúan roles de género, tanto para hombres y como para mujeres.

Para Sen (1990) el supuesto de que los ingresos de las mujeres mejoran su posición, se sustenta fundamentalmente en dos criterios: primero, eleva su bienestar y autoestima, y segundo, incrementa la percepción de otros miembros del hogar al valorar sus contribuciones. Sen (2000) también señala que el uso del microcrédito no es suficiente para impulsar procesos de empoderamiento sino se ve acompañado por una socialización del trabajo doméstico. Lejos de convertirse en un instrumento para atenuar la pobreza por capacidades, la incrementa. Es decir, las opciones de participación política y social se diluyen cuando las beneficiarias tienen que conciliar el trabajo doméstico, reproductivo y productivo. A partir de los resultados encontrados, se demuestra que las mujeres realizan dobles o triples cargas de trabajo, asumiendo en solitario la labor relacionada con el microcrédito y el trabajo reproductivo.

¿Cuál es la ganancia que obtienen las mujeres 
con los pequeños emprendimientos? La figura 2 da cuenta de esta información; 33\% obtiene entre un peso y $\$ 2000$ pesos. Otra cantidad semejante obtiene entre $\$ 2,001$ y $\$ 4,000$ pesos. Llama la atención que $25 \%$ de usuarias obtienen entre $\$ 4,000$ y $\$ 6,000$ pesos (véase la Figura 2).

Fuente: Elaboración propia con datos de la investigación, 2013.

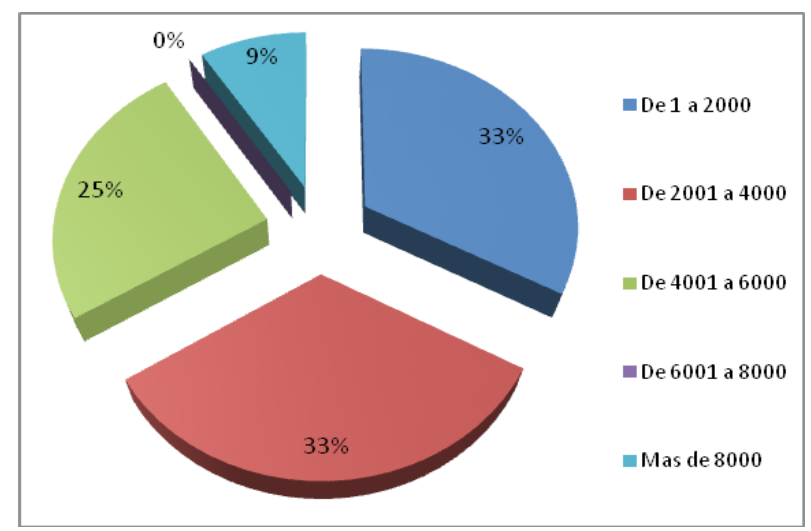

Figura 2. Ganancias de las mujeres,

según los esposos.

El argumento que se propuso al inicio era que a través de los micronegocios las mujeres podían alcanzarcierto grado de empoderamiento económico. Al respecto, Young (1991) y Kabeer (1998), señalan que sí es posible alcanzarlo aún con bajos niveles de ingresos, como los obtenidos por la mayoría de las mujeres rurales y urbanas marginales, siempre y cuando se desarrolle un potencial transformador. Para estas autoras, ello significa que la mujer valore sus ingresos y reconozca la importancia de sus contribuciones al hogar, alcanzando la capacidad de cuestionar, debilitar o transformar relaciones de género desiguales y estructuras de subordinación. Para Kabeer (1998), el concepto de potencial transformador se relaciona con la idea de poder interno que permite a los seres humanos desarrollar la habilidad de reconocer y desafiar desigualdades de género. Dos mujeres entrevistadas lo exponen:

[...] eso de ganar dinero a mí me da orgullo, de salir adelante, de ser una persona exitosa, es decir, mi orgullo es muy grande. Desde un principio que mis padres me permitieron ir a la escuela y ahora decir no, yo puedo, yo soy una persona emprendedora, yo soy una persona que ha tocado puertas y que no se ha quedado a llorar penas y que no tengo miedo [...] (Laura, 18 de enero de 2012).

[...] mi poder para las decisiones ahora creo que está igual al de mi esposo, a veces creo que hasta más, depende de la situación, ya los dos podemos tomar decisiones. En ocasiones digo, estas cosas las quiero así o necesito esto y se hace porque yo también estoy poniendo dinero para la casa, ya no es lo mismo [...] (Marcela, 28 de enero de 2012) (Citado en García et al., 2015, pp. 38-39).

No interesa aquí analizar los procesos de empoderamiento económico de las mujeres ya que se ha realizado en otros documentos ${ }^{13}$. Lo que se propone aquí es examinar lo que opinan los esposos/ compañeros de estas mujeres, sin embargo, con estos testimonios se puede observar que de alguna manera las mujeres han logrado mayor poder, tanto en la toma de decisiones en la microempresa, como en las decisiones de su hogar, sobre todo en la forma en que gastan y distribuyen el ingreso, aquí la pregunta es ¿Cómo han incorporado estos cambios los hombres? ¿Cómo se han adaptado y qué resistencias tienen? Es decir, si han surgido nuevas identidades, nuevas masculinidades.

\section{Perfil de los hombres compañeros/esposos de las microempresarias}

Los entrevistados fueron $20^{14}$, de ellos 19 estaban casados (iglesia o civil) y uno de ellos en unión libre. Desempeñan diversos oficios: uno es obrero, cinco trabajan en una fábrica o empresa; cinco son comerciantes, nueve atienden un negocio de microcrédito; dos hacen trabajos de albañilería, electricidad y herrería y otro es maestro. Respecto a las edades, 11 hombres dijeron tener entre veinte y cuarenta años, los otros nueve más de 41 años, cabe resaltar que el más joven tiene 21 años y el mayor 69. En la escolaridad, seis hombres dijeron tener la primaria, nueve secundaria, tres señalaron haber cursado la preparatoria, y sólo dos indicaron tener nivel universitario.

\footnotetext{
${ }^{13}$ Ver García, Zapata-Martelo, Valtierra y Garza (2014) y García, Ayala y Zapata (2015).

${ }^{14}$ Cuatro de los entrevistados no completaron la entrevista, aunque se incluyó lo que respondieron. Se negaron a expresar su posición respecto al trabajo doméstico y sobre los cambios en las masculinidades. Esta actitud refleja malestar y miedo ante el cuestionamiento de estos dos puntos.
} 
Fue importante conocer cuál es el aporte de los esposos a la reproducción del grupo doméstico, 14 de ellos indican que su esposa/compañera también aporta al gasto del grupo doméstico. Para conocer cuánto aportan ellos se utilizaron los mismos estratos que fueron empleados para el caso |de las mujeres. Primero, más del $50 \%$ de los esposos aportan entre $\$ 1$ y $\$ 2,000$ pesos y poco más del $30 \%$ entre $\$ 2,001$ y $\$ 4,000$ pesos. La sumatoria de estos dos indicadores da como resultado $94 \%$, es decir, la aportación de los esposos se ubica entre $\$ 1$ y $\$ 4,000$ pesos.

Se comparó el aporte de las mujeres y hombres, llama la atención que las mujeres aportan más al gasto familiar que los esposos, $25 \%$ de ellas dijeron aportar de 4001 a 6,000 pesos y en el caso de los hombres sólo $6 \%$ de ellos aportan la misma cantidad, de igual forma, $9 \%$ de las mujeres dijeron aportar más de 8,000 pesos, mientras que de los hombres entrevistados ninguno dijo aportar la misma cantidad. Por el contrario, ellos son quienes aportan el menor monto de ingresos, pues el 57\% de la muestra dijo aportar menos de 2,000 pesos.

El modelo tradicional de masculinidad establece como uno de sus postulados básicos que los hombres deben ser los proveedores de la economía. En la división genérica del trabajo, ellos son quienes se dedican al trabajo productivo y las mujeres el reproductivo, sin embargo, como se puede observar desde hace algunas décadas, esto no es así, pero el hecho de que ellos ya no sean los proveedores únicos y que no sean capaces de cubrir los gastos del grupo familiar también les genera conflictos, cuestionamientos hacia su masculinidad, hacia su capacidad y poder (véase la Figura 3).

En términos generales, las mujeres en condiciones de pobreza recurren al microcrédito cuando los ingresos de los hombres son insuficientes para sostener las necesidades más inmediatas, o cuando el responsable del hogar atraviesa por periodos de desempleo. Es decir, la trayectoria laboral de las mujeres está condicionada por las dinámicas de las y los integrantes del hogar.
Fuente: Elaboración propia.

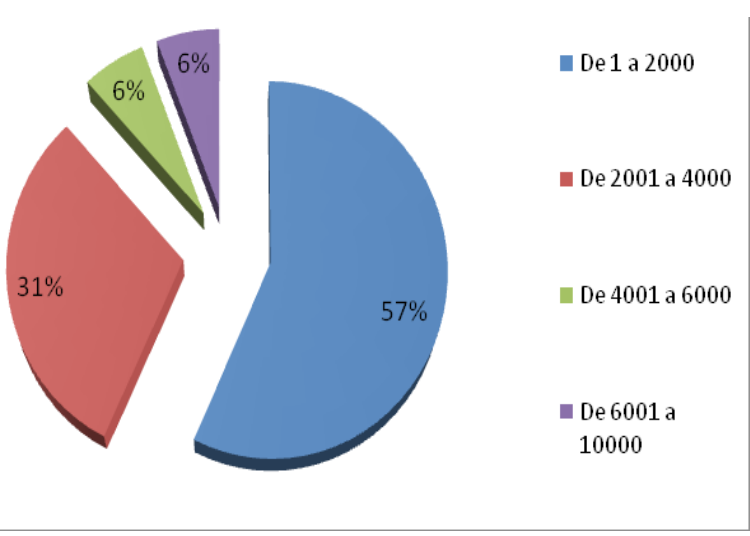

Figura 3. Recursos que los hombres aportan para el gasto del hogar.

\section{Voces de los esposos/compañeros ante los cambios de las microempresarias}

Aunque los hombres entrevistados pertenecen a distintas generaciones, muestran discursos similares respecto a lo que ha significado el microfinanciamiento de las mujeres. Coinciden en que ha habido cambios en los roles de género, que las mujeres tienen y deben tener más oportunidades, en la importancia de la educación para ellas, que hay una mayor incorporación de éstas en el mercado laboral, en la necesidad de tener relaciones más equitativas al interior de la familia. Sin embargo, estas afirmaciones se limitan a modificaciones en los discursos, pero no en la transformación de los mandatos de género, ya que son los hombres los que siguen ejerciendo el poder, quienes las supervisan y los que han posibilitado o no, el acceso de las mujeres, cuando ellas han mostrado capacidad. En consecuencia, el riesgo está en que con estos discursos se crean representaciones sociales, que hacen sospechar y ocultan, incluso, discursos vigentes sobre la discriminación de género. Es en esta ambivalencia en la que se plasman los laberintos del poder y se encubren relaciones de micromachismo, como lo denomina Bonino (2000).

Elestudio constató que las identidades masculinas indígenas están fundamentadas en un proceso educativo profundo y complejo, en el que intervienen 
diversas instituciones, entre ellas la familia patriarcal, la escuela, los medios de comunicación, las redes de amigos o de pares, entre otros. La educación está dirigida a internalizar y fortalecer los mandatos de ser proveedores, jefes de familia y tener cargos políticos/sociales en la comunidad, entre otros, pero las experiencias personales de los varones, así como las condiciones contextuales y coyunturales, dominadas por situaciones de precarización de los medios de producción y acceso a los recursos, imponen significados y prácticas diferenciadas de las masculinidades. En general, los hombres entrevistados se enfrentan al problema de condiciones económicas desfavorables, lo cual les limita asumir sus asignaciones de género. Por ejemplo, la fragilización económica de las responsabilidades de los varones en esa región se relaciona con el poco o nulo trabajo existente, con salarios raquíticos, la migración, discriminaciones y explotación por parte de otros hombres, sobre todo de los no indígenas, entre otras cuestiones.

Los entrevistados reconocen los grandes cambios macro y micro que han ocurrido y que generaron la apertura del mercado para las mujeres y les posibilitaron salir de la casa para incursionar en espacios que había sido del dominio casi exclusivo de los varones en los que adquirían su identidad de proveedores únicos. En el cuestionario que contestaron los 20 hombres, 13 mencionaron que el papel del hombre en la sociedad es proteger y cuidar a su familia y los otros respondieron que es él quien debetrabajar por el grupo doméstico. Estas respuestas son contradictorias con algunos de los testimonios. En el siguiente testimonio, se puede apreciar que, si bien en principio valora positivamente el aporte de la compañera, inmediatamente después lo desvaloriza y minimiza, considerando que éste solo sirve para los gastos superfluos [leche de chocolate] manteniendo para él la posición de proveedor único, posición que reafirma su masculinidad.

[...] ahorita ya en esta actualidad todos debemos aportar algo oiga, porque por decir si yo me llegara a quedar sin trabajo, quien va a mantener a mis hijos, o sea, yo no hablo por mí, sino por los demás y yo siento que es necesario que nos ayude también la mujer y así viviríamos más desahogadamente, no nos privaríamos de nada, por decir, si queremos una leche de chocolate pues nos la tomamos y sin en cambio, no más con mi puro sueldo va a haber muchas privaciones, no va a alcanzar para lo que queremos ("Enrique", comunicación personal, 4 de abril de 2012).

Similar posición se puede escuchar en los testimonios 2 y 3 , por una parte hay un reconocimiento de los cambios económicos y la dificultad de mantenerse como proveedor único, incluso señalando que las esposas/compañas tienen también la responsabilidad de la manutención. Se reconoce la incertidumbre que genera la economía. El discurso oculta la fragilidad del poder masculino al no lograr mantener la posición de proveedor único, pero minimiza el aporte de la mujer al hablar de los "centavitos" que ella trae a casa, aun cuando los datos recabados muestran que no son unos cuantos "centavos" los que aportan las mujeres, pues ellas colaboran incluso con más dinero que ellos. Desde esta perspectiva el aporte económico de las mujeres se visualiza sólo como una ayuda, como un ingreso extra que les permite comprar otras cosas, algunos "lujos" que no podrían tener si el único ingreso del hogar fuera el de los esposos/compañeros.

El otro informante siente que ha superado el machismo de forma radical, porque permite que su esposa trabaje, aunque lo señala como un sacrificio, donde él se tiene que doblegar (perder su poder) con tal de poder mantener una buena comida y mejores condiciones de vida en las que incluye un negocio próspero.

Pues bueno yo de mi parte ahorita como está la vida pues si digo que sí es bueno que también ella aporte o que ella desempeñe cualquier actividad que crea que conviene, yo no soy de esas personas que no pues aquí estate, ahorita como estamos en estos tiempos pues no cae mal un centavito que también ella aporte ("Rigoberto", comunicación personal, 24 de abril de 2012).

Pues si oiga, pero eso a mí no me importa, mientras estemos bien y comiendo lo que queremos eso a mí no me interesa. Y es que yo en lo personal he cambiado radicalmente, porque yo era de esos muy machistas, pero si queremos prosperar y tener una empresa exitosa nos tenemos no doblegar, pero si tenemos que ser uno más tranquilo ("Enrique", comunicación personal, 4 de abril de 2012). 
Salinas (2007) señala que los hombres elaboran un discurso proactivo, favorable al cambio de roles que se ha experimentado en la sociedad, que ha impulsado la incorporación de las mujeres al mercado laboral, pensando en las transformaciones como un proceso normal de evolución hacia un mayor protagonismo de ellas. Sin embargo, al verlo como un proceso de evolución de las mujeres, los hombres no se cuestionan cómo ellos también tienen que evolucionar, cómo deben reorganizarse en el grupo familiar y en las relaciones con su pareja, no cuestionan las nuevas formas de ser hombre, porque eso implica ceder y/o perder privilegios y poder.

Es evidente el malestar que algunos hombres experimentan ante los cambios macro y micro que les ha restado poder en espacios que ellos controlaban y donde adquirían su identidad. Aunque aceptan que ellas se involucren en los microproyectos, sienten que tienen que controlar los negocios de las esposas/ compañeras manteniendo la supervisión y vigilancia sobre las actividades económicas de ellas. Así lo dicen en los testimonios 4 y 5 . También reconocen, como en el caso del número 6 , que hay conflicto entre el dinero de ella y el de él, sin lugar a duda como respuesta a la individualización que impone el capitalismo y a lo que señala Bourdieu (2000) como elementos constitutivos del poder masculino que se mantienen hasta hoy en las cabezas de los individuos. Estas prácticas discriminatorias de los hombres persisten porque la situación estructural de desigualdad se mantiene, y hace que los hombres tengan mayor acceso al poder y a los privilegios que se desprenden de su posición Sambade (2010).

En este caso, más ella [maneja el dinero], igual, se dice que las mujeres administran mejor el dinero y en este caso, si la que lo administra mejor es ella, falta esto, esto lo vamos a destinar para esto otro, lo único que hago yo es como supervisar que administre bien ("Ernesto", comunicación personal, 24 de abril de 2012).

Bueno, en este caso, en el préstamo de ProMujer, la de la responsabilidad es ella, pero con el respaldo mío, es decir, cuando ella no alcanza a reunir el pago yo le doy, pero además, ella tiene su negocio y si no lo completa pues le digo, cuánto te falta, pues ahí está, o que gracias a Dios le fue bien y ahí tiene su pago pues adelante, pero siempre ha sido la cosa repartida entre los dos, nunca ha sido de que ya tienes tu préstamo, pues ya te amolaste a ver cómo le haces, o sea, nunca la he dejado sola en este caso ("Faustino", comunicación personal, 12 de junio de 2012).

Se ha llevado a la par, yo siento que si ha habido un equilibrio, no creo que yo haya tenido que levantar la voz o cosas así, lógico no, si ha habido conflictos de que tu dinero y mi dinero ("Rigoberto", comunicación personal, 12 de junio de 2012).

Nuevamente el discurso de los hombres es en "apoyo" a las actividades realizadas por las mujeres, pues de alguna manera les ha quitado el peso de la responsabilidad de proveedores únicos de la familia, mencionan que los dos aportan y se apoyan económicamente, pero se contradicen (en el apoyo a las mujeres) cuando mencionan que ellos son los que vigilan, supervisan, y de alguna manera siguen controlando el dinero. Se muestran los conflictos en que entra sus estereotipos de masculinidad, por un lado "permitir e incentivar" que las mujeres trabajen $\mathrm{y}$ tengan ingresos propios, pero por el otro no cuestionar sus privilegios, ni querer abandonarlos.

\section{¿Es el trabajo de ellas responsable de la duración de los matrimonios?}

Una característica del discurso contradictorio de los esposos/compañeros, que muestran los testimonios 7 y 8 , es el hecho de considerar que el aporte económico de las mujeres es fundamental debido a las condiciones económicas inciertas, al trabajo inestable. No obstante, es difícil que los hombres renuncien al poder que han tenido en la sociedad jerárquica construida con el patriarcado. Éste se ejerce en forma inmediata hacia la esposa y por lo tanto piensan que, si trabajan, son ellas las responsables de que los matrimonios duren menos. Un "piropo por parte de un galán” va en contra de su masculinidad, ven a las esposas/compañeras como objetos de su propiedad, que nadie puede mirar. En sus propias palabras lo expresan:

Mire, yo creo que sí, los matrimonios duraban más, porque precisamente las mujeres no salían 
a trabajar, porque solo estaban ligadas a los quehaceres domésticos y ahora por decir, salen las mujeres a trabajar y no falta algún galán que les suelte el piropo y que por eso si hay más divorcios hoy en día ("Porfirio", comunicación personal, 2 de marzo de 2012).

Mire, lo que pasa es que los hombres ahora no encuentran trabajo y el hombre es un poquito flojo y no más quiere que, si la mujer trabaja él ya no quiere trabajar, y entonces llega un momento en que las mujeres se hartan de llevar todo lo necesario a la casa y dice, pues prefiero dárselo a mis hijos y tu búscale a ver dónde ("Luis", comunicación personal, 21 de marzo de 2012).

Al igual que en otros trabajos como el realizado por Salinas (2007), se coincide en que, los testimonios de los hombres develan el malestar e incomodidad que les produce la incorporación de las mujeres a los espacios de poder que históricamente han sido ocupados por ellos, sean estos en el mercado laboral o en los espacios de decisión. Los hombres refuerzan en sus discursos la vigencia de las características esencialistas de las mujeres, las actividades de reproducción, las responsabilidades como madres y esposas. Dejan entrever el malestar de perder privilegios, como que ellas les sirvan como súbditas.

\section{Si no cumples los mandatos de la feminidad eres rebelde}

Los compañeros/esposos de las microempresarias reconocen que las mujeres han logrado sobresalir y han aportado a sus grupos domésticos. Algunos reconocen problemas que han tenido las mujeres y el papel que ellos juegan en esa situación. Parecería que reconocen lo negativo de la subordinación en la que las han mantenido. Esta actitud no es generalizada. Sin embargo, el hecho de que ellas hayan logrado cierto empoderamiento a medida que alcanzan sus propios objetivos y que participan en procesos decisorios, es visto como rebeldía y justifican de esta forma maltratos y violencia, como es el caso de los testimonios de Rigoberto y Porfirio:

Pues yo pienso que son igual, yo siento que sí, yo considero que lo que ha cambiado es que la mujer ha sabido sobresalir de ese yugo que tenía el hombre sobre ellas, que yo siento que finalmente es para bien, nada más que desgraciadamente algunas mujeres no lo han sabido encaminar hacia un bien, sino hacia una rebeldía y muchas veces el hombre por ser más fuertes las maltratan, no sé por tener más fuerza ("Rigoberto", comunicación personal, 24 de abril de 2012).

Yo siento que eso está muy mal, porque no es posible golpear a una mujer si lo que se supone es que la queremos, yo siento que a veces nos sentimos muy hombres y eso es lo que pasa a veces y qué malo es que una mujer no se pueda defender, y cuando se puede defender, pues desgraciadamente nos opacan cuando no estamos debidamente preparados para eso verdad, yo siento que cuando pasa eso, creo que no hay suficiente confianza para platicar ("Porfirio", comunicación personal, 2 de marzo de 2012).

Este tipo de testimonios evidencian las tensiones que están vivenciando los hombres respecto al empoderamiento femenino. Por un lado, se reconoce a las mujeres, pero por otro muestran temor de perder el control, de que ellas se rebelen y no puedan controlar las decisiones de las mujeres, es mejor que mantengan sus características "naturales", de femineidad, y con ello evitar el maltrato del varón. Existe una compleja dinámica por la cual los privilegios se abandonan de forma lenta y dispareja, a medida que los hombres perciben los beneficios de la igualdad de género y el empoderamiento de las mujeres (Ricardo, 2014), pero no es fácil para ellos ceder el poder, incluso en algunos casos, cuando se sienten amenazados en algún aspecto de su masculinidad, actúan de forma violenta.

Estudios como el de Ricardo (2014), han evidenciado cómo el que los hombres sientan que pierden poder puede tener efectos dañinos para ellos y para las mujeres en sus vidas, la frustración de los hombres con su sensación de falta de poder puede llevarlos a adoptar ciertas conductas violentas contra las compañeras del sexo femenino. Garda (2007) señala que actualmente existe una crisis a nivel de identidad, pues si la mujer no les hace caso entonces los hombres "no se sienten hombres", por lo que usan la violencia para dejar claro quién es el que manda. 


\section{Recelo por lo que hacen y por lo que dicen}

Para Bonino(2000)la ideología masculina supone que hombres y mujeres son diferentes y desiguales por naturaleza. Los hombres libres y racionales, las mujeres emocionales y dependientes, capacitadas para el trabajo reproductivo y de cuidado de los varones, por lo que les es propio el confinamiento permanente en la esfera privada. La ideología de la supremacía masculina justifica esta división sexual del trabajo y constituye un dispositivo de saberpoder que perpetúa la desigualdad social y política entre mujeres y varones. Ellos dueños de los cuerpos de sus esposas/compañeras, no pueden aceptar que ellas se demoren para regresar a casa, temen qué dirán las personas de su comunidad, porque piensan que eso disminuye su hombría, temen que ellas se capaciten y que dejen de ser sumisas y acaten su voluntad. Los testimonios de Rigoberto y Ernesto lo exponen, y sienten además que ellas no deben andar por la calle, como lo menciona Faustino:

Porque yo le digo a ella cuando vas a ProMujer, te tardas mucho, así puro chisme, pero está bien, estás aprendiendo y estás aprendiendo a expresarte allá con ellos. Pero si te van a decir qué es lo que vas a hacer, eso está mal, pero todo, todo lo que vas a aprender lo vas a hacer con razonamiento ("Rigoberto", comunicación personal, 24 de abril de 2012).

Cuando tiene uno su criterio bien definido y cuando uno sabe que no va a haber nada malo, para mí no es malo que mi esposa trabaje, siempre y cuando tuviera un horario y que dijera que trabaja de tales horas a tales horas y ella ya sabría que tendría que llegar a la casa, porque se tiene que hacer esto y se tiene que hacer lo otro ("Ernesto", comunicación personal, 18 de junio de 2012).

Luego cuando vengo con los compañeros de trabajo pues luego sale la plática y pues hemos dicho que es bueno que trabajen para que me ayude, pero hay muchos que decimos: ¿Para qué vamos a dejar que nuestra esposa trabaje, entonces yo para que trabajo? Lo único que va a pasar es que ande en la calle. Entonces yo para eso he sido muy reservado y nunca les he dicho que les conviene, yo para eso me considero muy reservado, luego me dicen que soy muy serio o que si estoy enojado, además como que he sido muy reservado ("Faustino", comunicación personal, 12 de junio de 2012).

\section{Control a través del trabajo doméstico}

La estructura más significativa en la interrelación entre economía, la política y la cultura es la división sexual del trabajo y por lo tanto la más significativa para definir la identidad de hombres y mujeres, como muestran los testimonios 14, 15 y 16. Los primeros la han gestado en el espacio público y ellas en el privado. Los cambios actuales trastocan esta división, porque las mujeres tienen necesidad y quieren participar en el trabajo remunerado. No obstante, el poder masculino no quiere perder el bienestar que siempre consiguió con los cuidados que se le proveen en el espacio doméstico y donde siempre estuvo favorecido. Se les escucha decir en los testimonios que ya no tienen la atención que se les brindaba en el pasado. Otros reniegan del trabajo doméstico, porque eso "no se les da". Es decir, ellas lo tienen que hacer, pero ellos mantienen los privilegios. El resultado, según García, ZapataMartelo, Valtierra y Garza (2014) son las triples jornadas que las mujeres realizan. Al desarrollar el trabajo en el hogar o en espacios muy cercanos a la casa-habitación, las mujeres buscan conciliar el trabajo de mercado con el reproductivo, logrando así una separación muy tenue que impide distinguir uno de otro.

Pues la verdad eso si me molesta a veces, pues como ella trabaja y para mí no hay esa atención, por decir, hay ocasiones en que llego cansado de trabajar y quiero de desayunar y me dice que tengo que esperar, porque es necesario hacerle un contrato a un cliente, que eso es importante, como ella hace los contratos, pues ella se encarga de decir, este contrato es para tal día, tanto de anticipo, cuál es el total, a qué hora quiere la inmobiliaria, bueno ya me toca desayunar solo. En cierta manera si hay cierta molestia, como cuando yo era quien trabajaba y era ella quien me dedicaba el tiempo a mí ("Enrique”, comunicación personal, 4 de abril de 2012).

Si porque no me atiende como antes y luego tengo que desayunar solo y luego hasta tengo que llamar a mis niños para darles de desayunar ("Ernesto", comunicación personal, 18 de junio de 2012).

Bueno, mucho, mucho yo no lo hago [el trabajo doméstico], no sé, yo digo que eso no se me da, a veces como que yo le huyo a eso, no 
estoy acostumbrado ("Faustino", comunicación personal, 12 de junio de 2012).

Para muchos otros hombres, su apoyo a la igualdad de género podría fundarse más en el interés propio o en la preocupación por su bienestar y sus relaciones personales, que porque realmente estén conscientes de que se deben establecer relaciones de mayor equidad. Por lo que no les queda otra opción que adaptar sus modos de relacionarse y colaborar. Ricardo (2014) señala que en el estudio "Men Who Care" se descubrió que los hombres que hacían una parte mayor del trabajo de cuidado no remunerado no lo hacían, en general, por razones "fundadas en los derechos"; más bien eran las circunstancias de la vida las que los obligaron a hacerlo, aunque con el tiempo llegaron a adoptar actitudes más equitativas.

\section{Conclusiones}

En el trabajo se han expuesto los testimonios que los 20 esposos/compañeros de mujeres otomíes microempresarias han reflexionado sobre estas nuevas actividades. Algunos tienen un discurso muy positivo sobre los cambios que se han dado en la economía y que ha permitido la inserción de las mujeres en el mercado de trabajo ya que reconocen indirectamente, que con los problemas actuales de la economía ellos no podrían proveer todas las necesidades de sus grupos domésticos, como lo hicieron en el pasado.

Pero en los discursos de los esposos/compañeros se nota la dificultad y el miedo que tienen al asimilar la independencia de las mujeres que podría resultar de estos espacios económicos, en los que ellas ahora gestionan recursos, participan en diversas actividades, se relacionan con otras mujeres $y$ hombres, y se reconocen en un proceso de cambio. Parecería que las relaciones de género tradicionales en público comienzan a resquebrajarse, aunque las relaciones de género al interior de los grupos domésticos no se cuestionan ni trastocan.

La actitud positiva de estos hombres otomíes no es generalizada, e incluso algunos discursos son contradictorios. Valoran lo que las mujeres hacen, pero se sienten relegados porque han perdido las atenciones que ellas les prestaban en el espacio doméstico. Al no hacerlo las obligan a dobles y triples jornadas de trabajo.

Ante el desarrollo del empoderamiento económico de las mujeres, es necesario nuevas formas de masculinidad, donde los hombres se cuestionen individual y colectivamente sobre lo que sus actos implican, es decir una deconstrucción de su masculinidad tradicional. Los caminos que conducen al compromiso de los hombres con la igualdad de género son muchos y a veces contradictorios: algunos se fundan en el propio interés, otros parcialmente en actitudes de protección (y por tanto son posiblemente patriarcales) y algunos en la adquisición de un sentido de la justicia de género y los derechos humanos universales (Ricardo, 2014).

Los resultados muestran que los esposos/ compañeros de las mujeres que participan en ProMujer tienen miedo ante los cambios, expresan conflictos y contradicciones sobre la nueva situación económica y las transformaciones de las mujeres, aunque no cuestionan su masculinidad. Existe miedo ante la pérdida de prerrogativas que mantuvieron por su posición patriarcal y contradicciones ante la independencia de las mujeres que por una parte les soluciona problemas económicos, pero por otra les implica retos a las relaciones de poder.

Los hombres cuestionan las actividades que hacen y no hacen las mujeres, las formas en que el trabajo de ellas afecta a sus privilegios e incluso su prestigio como hombres dentro de la familia y la forma en que otros hombres los ven, sin embargo, no cuestionan cómo ellos deben adaptarse a los cambios, cómo tener relaciones más equitativas, cómo ellos deben dejar de centrar su masculinidad en las mujeres.

\section{Referencias bibliográficas}

Bonino, Luis. (2000). Varones, género y salud mental: deconstruyendo la "normalidad" masculina. En Marta Segarra y Angels Carabí (Eds.), Nuevas masculinidades (pp. 41-64). Barcelona: Icaria.

Bourdieu, Pierre. (2000). La dominación masculina (Joaquín Jordá, Trad.). Barcelona: Anagrama. (Obra original publicada en 1998).

Campos, Álvaro y Salas, José. (2008) ¿Qué es la masculinidad? Su relación con el género. Nuestra forma de asumirla. En Carmen Hernández (Comp.), Género. Selección de lecturas (pp. 91-99). La 
Habana: Editorial Caminos.

Careaga, Gloria y Cruz, Salvador (Coords.). (2006). Debates sobre masculinidades. Poder, desarrollo, políticas públicas y ciudadanía. México: Programa Universitario de Estudios de Género, Universidad Nacional Autónoma de México.

Connell, Robert. (2008). El género como una estructura de la práctica social. En Carmen Hernández (Comp.), Género. Selección de lecturas (pp. 118-132). La Habana: Editorial Caminos.

Díaz-Cervantes, Rufino. (2015). Los estudios de las masculinidades indígenas en México y Latinoamérica. Contribuciones del Colegio de Postgraduados. Emma Zapata-Martelo y María Ayala-Carrillo (Coords.), Contribuciones de los estudios de género al desarrollo rural (pp. 122-155). Montecillo: Colegio de Postgraduados.

García, José. (2013). Y ellas trabajando a golpe de sol...y con el metate también. Relaciones de poder e independencia económica de las mujeres a partir de las microfinanzas rurales (Tesis doctoral). Colegio de Postgraduados, Montecillo, México.

García, José; Zapata-Martelo, Emma; Valtierra, Esteban y Garza, Laura. (2014). El microcrédito como una estrategia para atenuar la pobreza de las mujeres, ¿cuál pobreza? Estudios Fronterizos, 15(30), 97-126.

García, José; Ayala-Carrillo, María y Zapata-Martelo, Emma. (2015). ¿Empoderan las microfinanzas? Un estudio de caso en México. En Temis Gomes y Cynthia Miranda (Coords.), Arquiteturas de Gênero questões e debates (pp. 21-58). Brasil: Eduft.

García, Antonio y Lens, Jesús. (2007). Microcréditos. La revolución silenciosa. Barcelona: Editorial Debate.

Garda, Roberto. (2007). La violencia masculina desde la perspectiva de género visibilizando el género en la teoría social que reflexiona sobre la violencia. En Roberto Garda y Fernando Huerta-Rojas (Coords.), Estudios sobre la violencia masculina (pp. 59-114). México: Indesol y Hombres por la Equidad A.C.

Garza-Bueno, Laura. (2005). Usos y beneficios de los servicios microfinancieros. La perspectiva de las usuarias. En Congreso de la Asociación Mexicana de Estudios Rurales. Ponencia presentada en Oaxaca, México.

Herrera, Gioconda y Rodríguez, Lyli. (2001). Masculinidad y equidad de género desafíos para el campo del desarrollo y la salud sexual y reproductiva. En Xavier Andrade y Gioconda Herrera (Eds), Masculinidades en Ecuador (pp. 157-178). Quito: FLACSO y UNFPA.

Instituto Nacional de Estadística, Geografía e Informática (INEGI). (2013). Cencos económicos 2013. México: INEGI.
Kabeer, Naila. (1998). Realidades trastocadas. Las jerarquías de género en el pensamiento del desarrollo. México: Paidós.

Kaufman, Michael. (2008). Las paradojas del poder. En Carmen Hernández (Comp.), Género. Selección de lecturas (pp. 101-116). La Habana: Editorial Caminos.

Lacalle, Maricruz. (2002). Microcréditos: de pobres a microempresarios. Madrid: Ariel Social.

Montesinos, Rafael y Carrillo, Rosalía. (2010). Cambio cultural y masculinidades emergentes. Recuperado de http://www.fazendogenero.ufsc. br/9/resources/anais/1277227142 ARQUIVO MasculinidadesBRASIL.pdf.

Moreno, Beatriz; Garret, María y Fierro, Ulises. (2006). Otomíes del Valle del Mezquital: Pueblos Indígenas del México Contemporáneo. México: Comisión Nacional para el Desarrollo de los Pueblos Indígenas.

Navajas, Sergio y Tejerina, Luis. (2007). Las microfinanzas en América Latina y el Caribe: cuál es la magnitud del mercado. Washington, D.C.: Banco Interamericano de Desarrollo.

Organización de las Naciones Unidas para la Alimentación y la Agricultura (FAO). (2000). El estado mundial de la agricultura y la alimentación. Roma: FAO.

Ricardo, Christine. (2014). Hombres, masculinidades y cambios en el poder: Un documento de debate sobre la participación de los hombres en la igualdad de género desde Beijing 1995 hasta el año 2015. Recuperado de http://menengage.org/wp-content/uploads/2014/11/ Beijing-20-Hombres-Masculinidades-y-Cambios-enel-Poder-MenEngage-2014.pdf.

Salinas, Paulina. (2007). Los discursos masculinos como dispositivos de control y tensión en la configuración del liderazgo y empoderamiento femenino. Estudos Feministas, 15(3), 541-564.

Salinas, Paulina y Arancibia, Susana. (2006). Discursos masculinos sobre el poder de las mujeres en Chile. Sujetos y subjetividades. Última década, 14(25), 6590.

Sambade, Iván. (2010). Cuerpo, masculinidad y violencia: un análisis filosófico sobre la función socializadora de los medios de comunicación de masas en las democracias occidentales. En XLVII Congreso de Filosofía Joven. Ponencia presentada en la Universidad de Murcia, España. Recuperado de http:// congresos.um.es/filosofiajoven/filosofiajoven2010/ paper/view/6901.

Sen, Amartya. (2000). Desarrollo y libertad (Esther Rabasco y Luis Tohaira, Trads.). Barcelona: Planeta. (Obra original publicada en 1999).

Sen, Amartya. (1990). Gender and cooperative conflicts. Helsinki: Institute for Development Economic Research. 
Young, Kate. (1991). Reflexiones sobre cómo enfrentar las necesidades de las mujeres. En Patricia Portocarrero y Virginia Vargas (Comps.), Una nueva lectura: Género en el desarrollo (pp. 15-54). Lima: Flora Tristán.

Yunus, Muhammad. (1999). Hacia un mundo sin pobreza (Pablo Azócar, Trad.). Barcelona: Editorial Andrés Bello. (Obra original publicada en 1997).

Zapata-Galindo, Martha. (2001). Más allá del machismo. La construcción de las masculinidades. En Silke Helfrich (Coord.), Género, feminismo y masculinidad en América Latina (pp. 225-248). El Salvador: Fundación Heinrich Böll.

Zapata-Martelo, Emma; Vázquez-García, Verónica; Alberti-Manzanares, Pilar; Pérez-Nasser, Elia; López-Zavala, Josefina; Flores-Hernández, Aurelia; Hidalgo-Celerié, Nidia y Garza-Bueno, Laura.
(2003). Microfinanciamiento y empoderamiento de mujeres rurales: las cajas de ahorro y crédito en México. México: Plaza y Valdés Editores.

\section{Fuentes primarias}

Entrevista con "Enrique", 41 años, Tepatepec, Hidalgo, abril de 2012.

Entrevista con "Ernesto", 32 años, Chanpantongo, Hidalgo, abril y junio de 2012.

Entrevista con "Faustino", 63 años, Chilcuautla, Hidalgo, junio de 2012.

Entrevista con "Luis", 65 años, El cardonal, Hidalg, marzo de 2012.

Entrevista con "Porfirio", 34 años, El Carmen, Ixmiquilpan Hidalgo, marzo de 2012.

Entrevista con "Rigoberto", 44 años, Tolantongo, Ixmiquilpan, abril y junio de 2012. 